\title{
EFICIÊNCIA E SELETIVIDADE DO LACTOFEN EM MISTURA COM OUTROS LATIFOLICIDAS, NO CONTROLE DE PLANTAS DANINHAS NA CULTURA DA SOJA
}

\author{
Antônio Carlos de Barros ${ }^{1}$, Akira Ueda ${ }^{2}$ e Karl C. Schumm² \\ ' EMATER-GO. Caixa Postal 211. Jataí, GO 75800-012 \\ ${ }^{2}$ NOVARTIS. Caixa Postal 21460. São Paulo, SP 04602-970
}

\section{RESUMO}

Foi conduzido um ensaio com o objetivo de avaliar a eficiência e seletividade do lactofen em mistura com outros latifolicidas para o controle de plantas daninhas e os efeitos sobre algumas características da soja. O delineamento experimental adotado foi o de blocos ao acaso com quatro repetições e dez tratamentos, relacionados a seguir: oxasulfuron (45 g/ ha), cloransulam-methyl (37,9 g/ha), chlorimuron-ethyl $(15,0 \mathrm{~g} / \mathrm{ha})$, lactofen $(150 \mathrm{~g} / \mathrm{ha})$, oxasulfuron + lactofen $(37,5+96,0$ e 45,0+96,0 g/ha), cloransulam-methyl + lactofen $(29,4+96,0$ e 37,8+96,0 g/ha) e chlorimuron-ethyl + lactofen $(10,0+96,0 \mathrm{~g} /$ ha), aplicados em pós-emergência, além da testemunha absoluta. A corda-de-viola (Ipomoea grandifolia), a guanxuma (Sida rhombifolia) e a trapoeraba (Commelina benghalensis) foram eficientemente controladas pelas combinações de oxasulfuron + lactofen, cloransulam-methyl + lactofen e chlorimuron-ethyl + lactofen, obtendo-se controle mínimo de $82 \%$ aos 45 dias após os tratamentos (DAT). Os herbicidas aplicados isolados, de modo geral, proporcionaram controle inferior das plantas daninhas, exceto cloransulam-methyl. Os herbicidas provocaram intoxicação inicial às plantas de soja, porém aos 30 DAT a cultura apresentava-se recuperada. Os tratamentos utilizados não influenciaram significativamente a altura da planta e de inserção da primeira vagem, e estande final da soja. O peso de matéria seca das plantas daninhas foi influenciado pelos tratamentos, tendo-se obtido maior peso na testemunha absoluta. Não foram observadas diferenças significativas entre as produtividades obtidas nos tratamentos químicos, porém a interferência das plantas infestantes na testemunha absoluta provocou redução de $22 \%$ na produção de grãos, em relação àquela conseguida no tratamento chlorimuron-ethyl + lactofen $(10,0+96,0 \mathrm{~g} / \mathrm{ha})$. O índice de colheita mecânica nos tratamentos onde foram utilizadas as misturas foi bom, o que no ecossistema cerrado justifica o uso de combinações de herbicidas para o controle da vegetação daninha.

Palavras-chave: Ipomoea grandifolia, Commelina benghalensis, Sida rhombifolia, oxasulfuron, cloransulam-methyl, chlorimuron-ethyl.

\section{ABSTRACT \\ Efficiency and selectivity of lactofen mixed with other broadleaf herbicides in the control of weeds in soybean}

An experiment was carried out with the objective to evaluate the efficiency and selectivity of lactofen in conbination with other herbicides in the control of weeds and to study the effects of the mixtures on some soybean characteristics. The experimental design was a randomized complete block, with ten treatments and four replications. Treatments were: oxasulfuron (45 g/ha), oxasulfuron + lactofen $(37.5+96.0$ and $45.0+96.0 \mathrm{~g} / \mathrm{ha})$, cloransulam-methyl + lactofen $(29.4+96.0$ and $37.8+96.0$ $\mathrm{g} / \mathrm{ha}$ ), and two controls ( with and without hoeing). Ipomoea grandifolia, Sida rhombifolia and Commelina benghalensis were efficiently controlled by the combination of oxasulfuron + lactofen, cloransulam-methyl + lactofen and chlorimuronethyl + lactofen, with more than $82 \%$ control at 45 days after treatments. Herbicides aplied alone (not in combination) except 
for cloransulam-methyl, did not give good weed control. Treatments did not influence soybean height, first pod insertion height and final stand.

Weeds dry weight was higher in the control without hoeing. There was no productivity difference between the treatments with herbicides; however, the interference of weeds in the control without hoeing decreased productivity in $22 \%$ compared to the productivity in the treatment chlorimuron-ethyl + lactofen $(10+96 \mathrm{~g} / \mathrm{ha})$.

Key words: Ipomoea grandifolia, Commelina benghalensis, Sida rhombifolia, oxasulfuron, cloransulam-methyl, chlorimuron-ethyl.

\section{INTRODUÇÃO}

No Brasil a cultura da soja ocupou, na safra 1997/98, uma área de aproximadamente 12,9 milhões de hectares, alcançando rendimento médio de $2418 \mathrm{~kg} / \mathrm{ha}$ (CONAB, 1999). Dentre os inúmeros problemas da cultura da soja destacamse os relacionados à ocorrência das plantas daninhas, as quais além de reduzir a produtividade de grãos, dificultam a colheita mecânica, depreciando o produto colhido e aumentando o custo de produção. Não obstante, Crammer, citado por Deuber (1982), considera as plantas daninhas como sendo as maiores causadoras de prejuízos à produção de grãos da soja, quando comparadas com o ataque de parasitas animais e ocorrência de moléstias.

É enorme a diversidade de espécies de plantas daninhas no ecossistema cerrado e espécies como a trapoeraba (Commelina benghalensis), corda-de-viola (Ipomoea grandifolia) e guanxuma (Sida rhombifolia), dentre outras, tem sido freqüentes nas lavouras de soja do Estado de Goiás (Barros, 1990). Nos últimos anos verificou-se um aumento considerável na densidade populacional de várias espécies infestantes da cultura da soja, com ênfase para a trapoeraba e guanxuma. A trapoeraba tem-se tornado sério problema em muitas áreas agrícolas, principalmente em locais onde se adotou o sistema de plantio direto, possivelmente devido ao uso de sub doses de herbicidas dessecantes, os quais tem proporcionado controle deficiente dessa espécie infestante.

Por outro lado, o uso continuado de um mesmo herbicida também pode contribuir para a seleção de determinadas espécies infestantes, que se tornam paulatinamente tolerantes ao herbicida. Assim, DeFelice et al., citado por Fleck et al. (1997), afirmam que nos últimos 40 anos os herbicidas tem sido o maior instrumento de controle das plantas invasoras da cultura da soja.

Diferentes misturas de herbicidas, de aplicação em pós-emergência, tem sido recomendadas com sucesso para um controle mais eficiente da vegetação daninha. A mistura em tanque de chlorimuron-ethyl + lactofen tem sido largamente utilizada pelos sojicultores, proporcionando eficiente controle da maioria das espécies dicotiledôneas (Carvalho et al.,1997; Laca-Buendia e Lara, 1997). Em testes realizados com misturas de herbicidas latifolicidas tais como flumiclorac-pentil + chlorimuron-ethyl e oxasulfuron + lactofen, Barros \& Mendonça (1990), Osipe \& Nishimura (1997) e Souza et al. (1997) verificaram bom desempenho dos mesmos no controle da comunidade infestante de soja, proporcionando boa seletividade para a cultura. Por isso, é de suma importância a realização de pesquisas sobre o controle de plantas daninhas em diferentes regiões, a fim de obter alternativas que proporcionem um controle mais eficiente da comunidade infestante.

No presente trabalho estudou-se a eficiência de diferentes misturas de herbicidas aplicados em pós-emergência, no controle de plantas daninhas dicotiledôneas, bem como os possíveis efeitos tóxicos dessas misturas sobre algumas características da cultura da soja.

\section{MATERIAL E MÉTODOS}

O ensaio foi conduzido no município de Jataí, no ano agrícola 1998/99, na região fisiográfica Serra do Caiapó, no Sudoeste de Goiás, em solo sob vegetação de cerrado.

O delineamento adotado foi o de blocos ao acaso, com quatro repetições e dez tratamentos, relacionados na Tabela 1. A soja cv. Conquista foi semeada em 18/10/98, recebendo nos sulcos de plantio $300 \mathrm{~kg} / \mathrm{ha}$ de adubo da fórmula $02-20-18$.

Os herbicidas foram aplicados em pós-emergência, no dia 12/11/98, quando as plantas daninhas encontravamse com 4 a 6 folhas e a soja com 3 trifólios. No momento da aplicação dos produtos, que ocorreu das 8:45 às 9:20 horas, a temperatura do ar acusava $25^{\circ} \mathrm{C}$ e a umidade relativa $78 \%$. Para a aplicação foi utilizado um pulverizador costal pressurizado a $\mathrm{CO}_{2}$, com pontas de pulverização (bicos de jato plano) série 11002 , calibrados para $3,0 \mathrm{~kg} / \mathrm{cm}^{2}$ de pressão, consumindo 200 1/ha de calda.

As parcelas experimentais mediram $7 \mathrm{~m} \mathrm{x} 3 \mathrm{~m}=21$ $\mathrm{m}^{2}$, enquanto que a área útil para observações mediu $5 \mathrm{mx} 1$ $\mathrm{m}=5 \mathrm{~m}^{2}$. 
Tabela 1. Herbicidas utilizados, com as respectivas doses do produto comercial e do ingrediente ativo. Jataí-GO, 1998/99.

\begin{tabular}{lccccc}
\hline & Tratamento & & & \multicolumn{2}{c}{ Dose } \\
\hline Produto Comercial (p.c.) & Ingrediente Ativo (i.a.) & & l ou g/ha (p.c.) & g/ha (i a.) \\
\hline CHART 75 WG' $^{\prime}$ & Oxasulfuron & & 60 & 45,0 \\
PACTO & Cloransulam-methyl & & 45 & 37,8 \\
CLASSIC $^{1}$ & Chlorimuron-ethyl & & 60 & 15,0 \\
COBRA 240 CE & Lactofen & & 0,625 & 150,0 \\
CHART 75 WG + COBRA 240 CE' & Oxasulfuron + lactofen & & $50+0,4$ & $37,5+96,0$ \\
CHART 75 WG + COBRA 240 CE' & Oxasulfuron + lactofen & & $60+0,4$ & $45,0+96,0$ \\
PACTO + COBRA 240 CE' & Cloransulam-methyl + lactofen & & $35+0,4$ & $29,4+96,0$ \\
PACTO + COBRA 240 CE' & Cloransulam-methyl + lactofen & & $45+0,4$ & $37,8+96,0$ \\
CLASSIC + COBRA 240 CE' & Chlorimuron-ethyl + lactofen & & $40+0,4$ & $10,0+96,0$ \\
TESTEMUNHA & - & & - & - \\
\hline
\end{tabular}

' Foi adicionado à calda de pulverização o adjuvante EXTRAVON 0,2\% v./v.

Aos 15, 30 e 45 dias após a aplicação dos tratamentos (DAT) foram efetuadas avaliações visuais de controle das plantas daninhas, adotando-se a escala percentual, onde zero correspondeu a nenhum controle, e cem a controle total da vegetação daninha. Na mesma época foi avaliada a toxicidade à cultura da soja, adotando-se também a escala percentual, sendo zero equivalente a ausência de intoxicação e cem, dano total à cultura. No final do ciclo da soja, avaliou-se o índice de colheita mecânica, levando-se em consideração o grau de infestação das parcelas experimentais, além do porte das plantas invasoras, adotando-se a escala arbitrária: excelente, bom, médio, difícil e impossível.

Avaliou-se também as alturas de planta e de inserção da primeira vagem (média de 10 plantas), além do estande final (em $5 \mathrm{~m}^{2}$ ), peso de matéria seca das plantas daninhas e o rendimento de grãos.

Os parâmetros estande final, altura de plantas e de inserção da primeira vagem, rendimento de grãos de soja, além do peso de matéria seca das plantas daninhas, foram submetidos à análise de variância e as médias comparadas pelo teste de Tukey a $5 \%$ de probabilidade.

\section{RESULTADOS E DISCUSSÃO}

O complexo florístico de plantas daninhas da área experimental era constituído pela corda-de-viola (Ipomoea grandifolia) com densidade populacional média de 20 plantas $/ \mathrm{m}^{2}$, guanxuma (Sida rhombifolia) com 15 plantas $/ \mathrm{m}^{2}$ e trapoeraba (Commelina benghalensis) com 23 plantas $/ \mathrm{m}^{2}$.

A corda-de-viola foi eficientemente controlada pelo cloransulam-methyl (37,8 g/ha) e lactofen (150 g/ha), apli- cados isolados, além das misturas em tanque de oxasulfuron + lactofen $(37,5+96,0$ e 45,0+96,0 g/ha), cloransulam-methyl + lactofen $(29,4+96,0$ e 37,8+96,0 g/ha) e chlorimuron-ethyl + lactofen $(10,0+96,0 \mathrm{~g} / \mathrm{ha})$, obtendo-se controle mínimo de $85 \%$, aos 45 DAT (Tabela 2). Nos tratamentos contendo cloransulam-methyl + lactofen, houve melhor controle da corda-de-viola, em relação aos outros tratamentos químicos. Melhorança et al. (1998), também observaram bons níveis de controle da corda-de-viola com a utilização de lactofen + cloransulam-methyl $(120+30$ e $120+35 \mathrm{~g} / \mathrm{ha})$ e lactofen + chlorimuron-ethyl $(120+12,5$ e $175+12,5 \mathrm{~g} / \mathrm{ha})$.

Para a guranxuma, aos 45 DAT os tratamentos químicos que proporcionaram níveis de controle iguais ou superiores a $88 \%$ foram: cloransulam-methyl $(37,8 \mathrm{~g} / \mathrm{ha})$, cloransulam-methyl + lactofen $(29,4+96,0$ e $37,8+96,0 \mathrm{~g} /$ ha) e chlorimuron-ethyl + lactofen $(10,0+96,0 \mathrm{~g} / \mathrm{ha})$. A mistura oxasulfuron + lactofen apresentou índices de controle variando de 82 a $84 \%$ (Tabela 2).

Quanto a trapoeraba, verifica-se que cloransulammethyl $(37,8 \mathrm{~g} / \mathrm{ha})$, oxasulfuron + lactofen $(37,5+96,0 \mathrm{e}$ $45+96,0 \mathrm{~g} / \mathrm{ha})$ e cloransulam-methyl + lactofen $(29,4+96,0$ e $37,8+96,0 \mathrm{~g} / \mathrm{ha}$ ), proporcionaram eficiente controle dessa espécie infestante, equivalendo-se ao resultado obtido pelo chlorimuron-ethyl + lactofen $(10,0+96,0 \mathrm{~g} / \mathrm{ha})$, aos 45 DAT (Tabela 2). Tais resultados concordam com aqueles obtidos por Melhorança et al. (1998) com o uso de lactofen + chloransulam-methyl $(120+30$ e $120+35 \mathrm{~g} / \mathrm{ha})$, lactofen + chlorimuron-ethyl $(120+12,5$ e $175+12,8 \mathrm{~g} / \mathrm{ha})$, no controle da trapoeraba.

Analisando o controle geral da comunidade infestante verifica-se que de modo geral, as combinações de oxasulfuron + lactofen, cloransulam-methyl + lactofen e chlorimuron- 
Tabela 2. Resultados médios de controle das plantas daninhas, obtidos no ensaio com herbicidas em pós-emergência na cultura da soja. Jataí-GO, 1998/99.

\begin{tabular}{|c|c|c|c|c|c|c|c|c|c|c|}
\hline \multirow{4}{*}{ Tratamento } & \multirow{4}{*}{$\begin{array}{l}\text { Dose } \\
\text { (g/ha) }\end{array}$} & \multicolumn{9}{|c|}{ Controle $(\%)$} \\
\hline & & \multicolumn{9}{|c|}{ Dias Após os Tratamentos } \\
\hline & & 15 & 30 & 45 & 15 & 30 & 45 & 15 & 30 & 45 \\
\hline & & \multicolumn{3}{|c|}{$\begin{array}{c}\text { Ipomoea } \\
\text { grandifolia }\end{array}$} & \multicolumn{3}{|c|}{ Sida rhombifolia } & \multicolumn{3}{|c|}{$\begin{array}{c}\text { Commelina } \\
\text { benghalensis }\end{array}$} \\
\hline Oxasulfuron ${ }^{1}$ & 45,0 & 67 & 61 & 60 & 62 & 55 & 55 & 57 & 51 & 50 \\
\hline Cloransulam-methyl ${ }^{1}$ & 37,8 & 88 & 88 & 87 & 88 & 87 & 87 & 88 & 88 & 87 \\
\hline Chlorimuron-ethyl $^{1}$ & 15,0 & 80 & 78 & 75 & 63 & 58 & 57 & 80 & 78 & 74 \\
\hline Lactofen & 150,0 & 85 & 85 & 85 & 84 & 80 & 78 & 86 & 85 & 84 \\
\hline Oxasulfuron + lactofen ${ }^{1}$ & $37,5+96,0$ & 88 & 87 & 86 & 85 & 84 & 84 & 87 & 87 & 85 \\
\hline Oxasulfuron + lactofen ${ }^{1}$ & $45,0+96,0$ & 87 & 86 & 85 & 84 & 82 & 82 & 88 & 85 & 85 \\
\hline Cloransulam-methyl + lactofen ${ }^{1}$ & $29,4+96,0$ & 94 & 93 & 91 & 90 & 88 & 88 & 92 & 89 & 87 \\
\hline Cloransulam-methyl + lactofen ${ }^{1}$ & $37,8+96,0$ & 98 & 92 & 92 & 92 & 91 & 87 & 94 & 92 & 91 \\
\hline Chlorimuron-ethyl + lactofen ${ }^{1}$ & $10,0+96,0$ & 88 & 87 & 86 & 87 & 86 & 85 & 89 & 88 & 87 \\
\hline Testemunha & - & 0 & 0 & 0 & 0 & 0 & 0 & 0 & 0 & 0 \\
\hline
\end{tabular}

${ }^{1}$ Foi adicionado à calda de pulverização o adjuvante EXTRAVON $0,2 \%$ v./v.

ethyl + lactofen proporcionaram maiores níveis de controle das espécies invasoras em estudo, quando comparadas às aplicações isoladas dos produtos. Assim, é aconselhável no ecossistema cerrado, o uso de combinações de herbicidas latifolicidas para melhor controle da vegetação daninha.

Com relação à toxicidade, observa-se que apesar dos herbicidas provocarem intoxicação inicial às plantas de soja, houve rápida recuperação dessa cultura. Os maiores índices de injúrias dentro de limites aceitáveis na prática, foram observados nos tratamentos contendo lactofen, e portanto, nas doses testadas, os herbicidas foram seletivos para a cultura da soja (Tabela 3). Nesse sentido, Laca-Buendia \& Ferreira (1998), também verificaram sintomas iniciais de intoxicação às plantas de soja devido ao uso de oxasulfuron + lactofen e chlorimurom-ethyl + lactofen, com rápida recuperação da cultura. Barros \& Mendonça (1990), observaram sintomas de intoxicação iniciais à cultura da soja, provocados pela mistura de lactofen + chlorimuron-ethyl.

Nos tratamentos onde foram utilizadas as combinações de latifolicidas e cloransulam-methyl e lactofen aplicados isoladamente, obtiveram-se bons índices de colheita (Tabela 3). Na testemunha o índice foi "difícil" principalmente devido a presença da corda-de-viola, que é uma planta cujo ciclo termina depois da cultura da soja, tendendo a criar problema na colheita, quando a infestação é significativa (Kissmann, 1992).

A aplicação dos produtos influenciou significamente o peso de matéria seca das plantas daninhas no final do ciclo da soja (Tabela 3). O menor peso de matéria seca foi obtido no tratamento cloransulam-methyl + lactofen
$(29,4+96,0 \mathrm{~g} / \mathrm{ha})$ que não diferiu estatisticamente dos outros tratamentos químicos, com exceção daquele que recebeu oxasulfuron (45 g/ha), sendo que o maior peso de matéria seca foi obtido na testemunha.

A soja cv. Conquista apresentou rápido crescimento, dificultando o crescimento das plantas daninhas nas parcelas tratadas com herbicidas. Aquelas que não foram eliminadas pelos herbicidas, apresentaram injúrias severas, devido ao sombreamento causado pela soja, que prejudicou a recuperação das plantas daninhas, em especial onde se utilizou as combinações de herbicidas.

Das três espécies avaliadas, a trapoeraba foi a que contribuiu com o maior peso de matéria seca, pois as outras espécies que não foram eliminadas pelos herbicidas, a cultura da soja abafou-as, eliminando-as quase totalmente.

A aplicação dos tratamentos não influenciou significativamente o estande final (Tabela 3) nem as alturas de planta e de inserção da primeira vagem (Tabela 4). LacaBuendia \& Ferreira (1998), em ensaio com misturas de herbicidas, também não constataram diferenças significativas entre as alturas de plantas de soja, em função dos tratamentos aplicados.

Quanto ao rendimento de grãos, não foram verificadas diferenças significativas entre os tratamentos químicos (Tabela 4), levando a crer que a aplicação dos herbicidas isolados proporcionou, de modo geral, menores índices de controle da vegetação daninha. Mesmo assim, a ação herbicida associada ao efeito cultural da soja foi suficiente para manter a interferência das plantas infestantes sobre a cultura, em 
Tabela 3. Resultados médios de toxicidade, índice de colheita, peso de matéria seca das plantas daninhas e estande final obtidos no ensaio com herbicidas na cultura da soja. Jataí-GO, 1998/99.

\begin{tabular}{|c|c|c|c|c|c|c|c|}
\hline \multirow{3}{*}{ Tratamento } & \multirow{3}{*}{$\begin{array}{l}\text { Dose } \\
\text { (g/ha) }\end{array}$} & \multirow{2}{*}{\multicolumn{3}{|c|}{$\frac{\text { Toxicidade }}{\text { DAT }}$}} & \multirow{3}{*}{$\begin{array}{c}\text { Índice de } \\
\text { colheita } \\
\text { mecânica }\end{array}$} & \multirow{3}{*}{$\begin{array}{c}\text { Peso de } \\
\text { matéria seca } \\
\text { das plantas } \\
\text { daninhas } \\
\left(\mathrm{g} / \mathrm{m}^{2}\right)\end{array}$} & \multirow{3}{*}{$\begin{array}{l}\text { Estande final } \\
\left(\text { plantas } / \mathbf{m}^{2}\right)\end{array}$} \\
\hline & & & & & & & \\
\hline & & 15 & 30 & 50 & & & \\
\hline Oxasulfuron ${ }^{1}$ & 45,0 & 5 & 0 & 0 & Médio & $49,73 b^{2}$ & $130 a^{2}$ \\
\hline Cloransulam-methyl $^{1}$ & 37,8 & 5 & 0 & 0 & Bom & $20,12 \mathrm{bc}$ & $135 \mathrm{a}$ \\
\hline Chlorimuron-ethyl ${ }^{1}$ & 15,0 & 6 & 0 & 0 & Médio & $44,01 \mathrm{bc}$ & $132 \mathrm{a}$ \\
\hline Lactofen & 150,0 & 18 & 0 & 0 & Bom & $35,77 \mathrm{bc}$ & $133 \mathrm{a}$ \\
\hline Oxasulfuron + lactofen ${ }^{1}$ & $37,5+96,0$ & 15 & 0 & 0 & Bom & $18,21 \mathrm{bc}$ & $133 \mathrm{a}$ \\
\hline Oxasulfuron + lactofen ${ }^{1}$ & $45,0+96,0$ & 17 & 0 & 0 & Bom & $14,69 \mathrm{bc}$ & $136 \mathrm{a}$ \\
\hline Cloransulam-methyl + lactofen ${ }^{1}$ & $29,4+96,0$ & 14 & 0 & 0 & Bom & $6,75 \mathrm{c}$ & $135 \mathrm{a}$ \\
\hline Cloransulam-methyl + lactofen ${ }^{1}$ & $37,8+96,0$ & 15 & 0 & 0 & Bom & $7,08 \mathrm{bc}$ & $133 \mathrm{a}$ \\
\hline Chlorimuron-ethyl + lactofen ${ }^{1}$ & $10,0+96,0$ & 16 & 0 & 0 & Bom & $16,23 \mathrm{bc}$ & $134 \mathrm{a}$ \\
\hline Testemunha & - & 0 & 0 & 0 & Dificil & $117,31 \mathrm{a}$ & $130 \mathrm{a}$ \\
\hline C.V \% & - & - & - & - & & 63,03 & 7,4 \\
\hline DMS & - & - & - & - & & 42,66 & 25,2 \\
\hline F (Tratamentos) & - & - & - & - & & $10,96 * *$ & $0,17 \mathrm{~ns}$ \\
\hline
\end{tabular}

' Foi adicionado à calda de pulverização o adjuvante EXTRAVON $0,2 \%$ v./v.

${ }^{2}$ Médias nas colunas seguidas das mesmas letras, não diferem significativamente entre si, pelo teste de Tukey a 5\% de probabilidade.

Tabela 4. Resultados médios de alturas de plantas e inserção da $1^{\text {a }}$ vagem, rendimento de grãos e produção relativa obtidos no ensaio com herbicidas aplicados em pós-emergência na cultura da soja. Jataí-GO, 1998/99.

\begin{tabular}{|c|c|c|c|c|c|}
\hline \multirow{2}{*}{ Tratamento } & \multirow{2}{*}{$\begin{array}{l}\text { Dose } \\
\text { (g/ha) }\end{array}$} & \multicolumn{2}{|c|}{$\begin{array}{c}\text { Altura } \\
(\mathrm{cm})\end{array}$} & \multirow{2}{*}{$\begin{array}{c}\text { Rendimento } \\
\text { de grãos } \\
\text { (kg/ha) }\end{array}$} & \multirow{2}{*}{$\begin{array}{c}\text { Produção } \\
\text { relativa } \\
(\%)\end{array}$} \\
\hline & & Plantas & $\begin{array}{l}\text { Inserção } \\
1^{\mathrm{a}} \text { vagem }\end{array}$ & & \\
\hline Oxasulfuron $^{1}$ & 45,0 & $74,75 a^{2}$ & $22,50 a^{2}$ & $2667 a^{2}$ & 99,2 \\
\hline Cloransulam-methyl $^{1}$ & 37,8 & $76,26 \mathrm{a}$ & $23,50 \mathrm{a}$ & 2627 a & 97,8 \\
\hline Chlorimuron-ethyl ${ }^{1}$ & 15,0 & 79,75 a & 23,25 a & 2635 a & 98,1 \\
\hline Lactofen & 150,0 & $76,75 \mathrm{a}$ & $22,50 \mathrm{a}$ & 2687 a & 100,0 \\
\hline Oxasulfuron + lactofen ${ }^{1}$ & $37,5+96,0$ & $77,25 \mathrm{a}$ & $23,25 \mathrm{a}$ & 2662 a & 99,1 \\
\hline Oxasulfuron + lactofen ${ }^{1}$ & $45,0+96,0$ & $77,25 \mathrm{a}$ & $23,50 \mathrm{a}$ & 2647 a & 98,5 \\
\hline Cloransulam-methyl + lactofen ${ }^{1}$ & $29,4+96,0$ & $77,25 \mathrm{a}$ & $23,00 \mathrm{a}$ & 2662 a & 99,1 \\
\hline Cloransulam-methyl + lactofen ${ }^{1}$ & $37,8+96,0$ & $77,50 \mathrm{a}$ & $23,50 \mathrm{a}$ & 2690 a & 100,1 \\
\hline Chlorimuron-ethyl + lactofen ${ }^{1}$ & $10,0+96,0$ & $75,75 \mathrm{a}$ & $24,25 \mathrm{a}$ & 2687 a & 100,0 \\
\hline Testemunha & - & $77,00 \mathrm{a}$ & $25,25 \mathrm{a}$ & $2087 \mathrm{~b}$ & 77,7 \\
\hline C.V \% & - & 6,65 & 9,64 & 4,16 & - \\
\hline DMS & - & 13,19 & 5,77 & 279,9 & - \\
\hline F (Tratamentos) & - & $0,31 \mathrm{~ns}$ & $0,35 \mathrm{~ns}$ & $7,04 * *$ & - \\
\hline
\end{tabular}

${ }^{1}$ Foi adicionado à calda de pulverização o adjuvante EXTRAVON $0,2 \%$ v./v.

${ }^{2}$ Médias nas colunas seguidas das mesmas letras, não diferem significativamente entre si, pelo teste de Tukey a $5 \%$ de probabilidade. 
níveis que não ocasionaram prejuízos significativos a produção de grãos dessa oleaginosa. Já a interferência da vegetação daninha na testemunha absoluta (sem capina), provocou rendimento de grãos estatisticamente inferior a todos os outros tratamentos. A produção de grãos obtida na testemunha foi $22 \%$ inferior àquela conseguida no tratamento padrão chlorimuron-ethyl + lactofen $(10,0+96,0 \mathrm{~g} / \mathrm{ha})$.

\section{CONCLUSÃO}

Os resultados do experimento permitem concluir pela viabilidade da utilização das combinações de oxasulfuron + lactofen, cloransulam-methyl + lactofen e chlorimuron-ethyl + lactofen, para o controle da corda-de-viola, guanxuma e trapoeraba. Os herbicidas foram seletivos para a cultura da soja. As alturas das plantas e de inserção da primeira vagem e estande final não foram influenciados significativamente pelos tratamentos. Já o peso da matéria seca das plantas daninhas, foi influenciado pela aplicação dos produtos. O índice de colheita mecânica nos tratamentos químicos variou de médio a bom. Não se observaram diferenças significativas entre as produtividades conseguidas nos tratamentos químicos. A testemunha absoluta alcançou um rendimento de grãos $22 \%$ menor do que aquele obtido no tratamento chlorimuron-ethyl + lactofen.

\section{LITERATURA CITADA}

BARROS, A. C. de. Avaliação da eficiência e seletividade da mistura bentazon + fomesafen no controle de plantas daninhas dicotiledôneas na cultura da soja. GoiâniaGO: EMGOPA-DID, 1991. 8 p. (EMGOPA: Comunicado Técnico, 31).

BARROS, A. C. de. Plantas daninhas na cultura da soja, em áreas sob vegetação de cerrado. Agrotécnica: defesa vegetal e animal, São Paulo, n. 7, p.5-7. 1990.

BARROS, A. C. de; MENDONÇA, J. L. de. Misturas de herbicidas pós-emergentes para o controle de plantas daninhas dicotiledôneas na cultura da soja. Goiânia,GO: EMGOPA-DID, 1990, 11p. (EMGOPA: Comunicado Técnico, 28).

CARVALHO, J. A.; MARICONDI, P. F.; SANTOS, V. L. M. Eficácia do herbicida chlorimuron- ethyl e misturas no controle de Mimosa pudica e na seletividade à cultura da soja "Seriema". In: CONGRESSO BRASILEIRO DA CIÊNCIA DAS PLANTAS DANINHAS,
21, 1997, Caxumbu. Resumos...Viçosa: SBCPD, 1997. p. 59.

CONAB. Indicadores da Agropecuária. Março/99. Brasília, DF, Ano 8, no 3, 1999. p.11.

DEUBER, R. Controle de plantas daninhas na cultura da soja. In: FUNDAÇÃO CARGIL. A soja no Brasil Central. 2 ed. Campinas, SP, 1982. p. 367-392.

FLECK, N. G.; CUNHA, M. M. DA.; VARGAS, L. Doses reduzida de clethodin no controle de papuã na cultura da soja, em função da época de aplicação. Planta Daninha, v. 15, n.1, p. 18-24. 1997.

LACA-BUENDIA, J. P.; FERREIRA, J. C. Seletividade e eficiência biológica da mistura dos herbicidas oxasulfuron + lactofen no controle pós-emergente de plantas daninhas na cultura da soja. XI REPEC, Resultados de Pesquisas. Ilha Solteira, SP: EMBRAPA e FEIS/UNESP, 1998. p.143-151.

LACA-BUENDIA, J. P.; LARA, J. F. R. Eficácia e seletividade do oxasulfuron aplicado na pós-emergência, para o controle de plantas daninhas latifoliadas anuais na cultura da soja (Glycine $\max$ (L.) Merril.). In: CONGRESSO BRASILEIRO DA CIÊNCIA DAS PLANTAS DANINHAS, 21, 1997. Caxambu. Resumos...Viçosa: SBCPD, 1997, p. 101.

KISSMANN, K. G. Plantas infestantes e nocivas: Tomo I. São Paulo: BASF Brasileira S.A., 1992. p. 550-553.

MELHORANÇA, A.L.; MUNHOZ, I. A.; MELHORANÇA FILHO, A. L. Efeito do herbicida lactofen aplicado em mistura com outros herbicidas latifolicidas no controle de plantas daninhas na soja. XI REPEC, Resultados de Pesquisa. Ilha Solteira, SP: EMBRAPA e FEIS/ UNESP, 1998. p. 51-58.

OSIPE, R.; NISHIMURA, M.; LOPES, D. Avaliação da eficiência e seletividade de herbicidas aplicados em misturas de tanque, em pós-emergência na cultura da soja. In: CONGRESSO BRASILEIRO DA CIÊNCIA DAS PLANTAS DANINHAS, 21, 1997, Caxambu Resumos...Viçosa: SBCPD, 1997. p. 136.

SOUZA, I. F.; ARGENTA, J. A.; BARROSO, A. L. L. Misturas de herbicidas de pós-emergência para o controle de espécies de folhas largas em soja. In: CONGRESSO BRASILEIRO DA CIÊNCIA DAS PLANTAS DANINHAS, 21, 1997, Caxambu. Resumos...Viçosa: SBCPD, 1997. p. 136. 